\title{
The effects of amphetamine on blocking
}

\author{
D. OHAD, R. E. LUBOW, I. WEINER, and J. FELDON \\ Tel-Aviv University, Ramat-Aviv, Tel-Aviv, Israel
}

\begin{abstract}
In the blocking paradigm, prior conditioning to one stimulus, $\mathrm{A}$, interferes with conditioning to a second stimulus, $B$, when the two are reinforced as a compound in subsequent training. The present experiment employed a conditioned emotional response (CER) procedure with rats to examine the effects of $1.5 \mathrm{mg} / \mathrm{kg} \mathrm{dl}$-amphetamine on blocking. The drug was administered in a $2 \times 2$ design, that is, drug or no drug in the single stimulus conditioning stage and drug or no drug in the compound conditioning stage. Administration of the drug in either stage alone disrupted blocking. In contrast, animals that received amphetamine in both stages of the blocking paradigm showed a normal blocking effect.
\end{abstract}

Amphetamine-induced behavioral changes in animals frequently have been suggested as a model of human psychosis (e.g., Segal \& Janowsky, 1978; Segal \& Schuckit, 1983). The animal amphetamine model of schizophrenia has provided valuable information in regard to the pharmacological basis and treatment of the disorder. However, the model has relied primarily on one aspect of amphetamine-induced disturbances, namely stereotyped behavior. Although stereotyped behavior appears in some forms of schizophrenia, there are additional characteristics of the disorder that have been widely commented upon in the human literature but have not been investigated within the animal amphetamine model. One such conspicuous characteristic is an attentional dysfunction, or, more specifically, an inability to ignore irrelevant information (e.g., Bleuler, 1966; Chapman \& Chapman, 1973; Garmezy, 1977; Kokkinidis \& Anisman, 1980; Matthysse, Spring, \& Sugarman, 1979; McGhie, 1977; Venables, 1964). The development of a useful animal model of schizophrenia would seem to require the isolation of a similar amphetamine-induced deficit in attentional processes.

In line with this approach, Solomon et al. (1981) and Weiner, Lubow, and Feldon $(1981,1984)$ investigated the effects of amphetamine on latent inhibition (LI) (Lubow, 1973). In LI experiments, repeated exposure to a nonreinforced stimulus renders this stimulus ineffective for subsequent learning. The phenomenon of $\mathrm{LI}$ is considered to reflect a process of learning not to attend to, or to ignore, irrelevant stimuli (Lubow, Weiner, \& Schnur, 1981; Mackintosh, 1973, 1975; Moore, 1979), and is thus highly relevant for assessing schizophreniclike attentional deficits. Indeed, Solomon et al. (1981) and

This study was supported by grants from the Scottish Rite Schizophrenia Research Program, NMJ, USA, to R. E. Lubow and J. Feldon, and the Israel Academy of Sciences-Basic Research Fund to I. Weiner. The authors gratefully acknowledge the careful typing of Paula van der Werff. The authors' address is: Department of Psychology, TelAviv University, Ramat-Aviv, Tel-Aviv, Israel.

-Article accepted by previous editor, Patricia Morgan Meyer
Weiner et al. $(1981,1984)$ showed that LI was abolished by amphetamine.

Following the Solomon et al. (1981) study of LI, Crider, Solomon, and McMahon (1982) tested the effects of amphetamine on blocking. In blocking, prior conditioning to one stimulus, $\mathrm{A}$, retards subsequent conditioning to a second stimulus, $\mathrm{B}$, when the $\mathrm{AB}$ compound is reinforced (Kamin, 1968, 1969). One of the leading interpretations of blocking maintains that this phenomenon is due to the fact that the added element, B, provides no new information regarding reinforcement (Mackintosh, 1975, 1983). In this view, blocking is similar to $\mathrm{LI}$ in that the animal must learn to ignore an irrelevant (added) stimulus. Crider et al. (1982) argued that if a similar process of learning to ignore an irrelevant stimulus takes place in both $\mathrm{LI}$ and blocking, then amphetamine should also disrupt blocking. This expectation was supported by their results.

On the basis of their findings in the LI and blocking paradigms, Solomon et al. (1981) and Crider et al. (1982) concluded that animals under amphetamine were incapable of ignoring irrelevant stimuli. However, additional LI experiments carried out in our laboratory (Weiner et al., 1981, 1984) did not support this conclusion. In these experiments, we showed that LI was disrupted only when amphetamine was administerd in both the preexposure and conditioning stages. When drug administration was confined to the preexposure stage, in which learning to ignore the irrelevant stimulus takes place, LI was left intact. These results indicate that amphetamine does not disrupt animals' ability to learn to ignore an irrelevant stimulus, but instead disrupts their ability to respond to this stimulus as irrelevant in subsequently encountered situations.

In view of this finding, in the present experiment we investigated the effects of amphetamine on blocking, using the approach employed with LI; that is, we administered the drug separately in each stage of the blocking paradigm (single stimulus conditioning and compound conditioning) as well as in both stages. This method was useful in elucidating the conditions under which amphetamine disrupts LI, and one might expect to find similar results 
for blocking. The drug dose was $1.5 \mathrm{mg} / \mathrm{kg} \mathrm{dl-}$ amphetamine, which was found to abolish LI under a variety of conditions (Weiner et al., 1981, 1984, 1986).

\section{METHOD}

\section{Subjects}

The subjects were 59 male Wistar rats (Tel-Aviv University Medical School) approximately 90-100 days of age. They were housed one to a cage under reverse cycle lighting for the duration of the experiment.

\section{Apparatus}

Four Campden Instruments Skinner boxes (Model 410/P) set in sound-attenuating chambers (Model 412) were used. Each was equipped with a single lever and a recessed food magazine. Rewards were Campden Instruments $45-\mathrm{mg}$ food pellets. Scrambled shock of $1 \mathrm{~mA}$ intensity and $0.5 \mathrm{sec}$ duration could be applied to the grid floor from a Campden Instruments shock source (Model 521C) and a shock scrambler (Model 512S). The two conditioned stimuli (CSs) were white noise, generated by a Campden Instruments white noise generator (Model 530) and delivered through a loudspeaker at $70 \mathrm{~dB}$ as measured next to the lever, and a light, produced by a 24-V bulb located in the ceiling of the box. Both CSs were 3 min long. A Rockwell Aim 65 microprocessor was used for equipment programming and data recording.

\section{Experimental Design and Procedure}

Two weeks prior to the beginning of the experiment, the rats were placed on a 23-h food deprivation schedule that continued throughout the experiment. In this stage, feeding took place at $10 \mathrm{a} . \mathrm{m}$., the median time of the future experimental sessions. During the experiment, feeding took place half an hour after the daily session. On the first 3 days, all rats were given $1 \mathrm{~h}$ of magazine training, during which food was delivered independently of the animals' responding on a variable-interval (VI) 60-sec schedule. A continuous reinforcement schedule (CRF) for barpresses was superimposed on this schedule. The VI 60-sec free food schedule was discontinued once the rats emitted 20 barpresses. The CRF was discontinued when the rats emitted 5 barpresses. The animals were then placed on a progressive fixed-ratio (FR) schedule starting at FR 2 and incrementing by 2 after every fifth reinforcement until FR 18 was reached or until the 1-h session was terminated. This training was followed by 10 daily 1 -h sessions of VI 60 -sec leverpress training. This schedule remained in effect for the remainder of the experiment.

Before the start of Stage 1 conditioning, the animals were divided into two training conditions: blocking and control. In each training condition, the animals were subdivided into four drug conditions according to whether they received drug (amphetamine) or saline in Stage 1, and drug or saline in Stage 2: saline-saline (SS), salinedrug (SD), drug-saline (DS), and drug-drug (DD). As there were no appreciable differences between subjects' response rates, group assignment was made at random. On the day before Stage 1 conditioning started, the animals received two exposures each to the light and white noise stimuli. The first stage of conditioning lasted 4 days. Animals in the blocking group received, in each daily 60-min session, four noise-shock pairings, presented $9,21,33$, and 45 min after the beginning of the session. Noise offset was concurrent with shock onset. Animals in the control group continued to respond on a VI 60-sec schedule and did not receive any conditioning trials. Stage 2 lasted 2 days. On each day, both groups received four reinforced noise-light trials presented at the same time intervals as in Stage 1. Following compound training, all animals received one test session with four light-shock pairings presented at the same time intervals as in the previous stages.

\section{Drug Injections}

Two days prior to the beginning of Stage 1, all subjects were injected with $0.2 \mathrm{ml}$ saline IP $10 \mathrm{~min}$ before the session. All animals then received, on the 4 days of Stage 1 and the 2 days of Stage 2, daily IP injections of the appropriate solution: animals in the drug condition received $1.5 \mathrm{mg} / \mathrm{kg}$ of dl-amphetamine sulphate dissolved in $1 \mathrm{ml}$ of saline, and animals in the saline condition received an equivalent volume of saline. All injections were given $10 \mathrm{~min}$ prior to the start of the daily session. No drugs were administered in the test session.

\section{RESULTS}

Performance on conditioning and test trials was indexed by a suppression ratio, $A /(A+B)$, in which $A$ is the number of responses during the $C S$ and $B$ is the number of responses during the $3 \mathrm{~min}$ preceding the CS. A suppression ratio of 0.0 indicates complete suppression and a ratio of 0.5 indicates no change in response rate from the pre-CS to the CS period.

\section{Stage 1}

Figure 1 presents the mean suppression ratios over eight blocks of two trials in the two drug conditions (drug, saline) for the blocking and control groups. Animals in the blocking groups exhibited an increase in suppression over the 16 conditioning trials, whereas no suppression was evident in the control groups. This finding was supported by the results of a $2 \times 2 \times 16$ ANOVA-with main factors of drug in Stage 1 (amphetamine, saline) and group (control, blocking) and a repeated measures factor of trialswhich yielded a significant main effect of group $[F(1,55)$ $=350.14, p<.001]$, as well as a significant group $\times$ trials interaction $[F(15,825)=14.13, p<.001]$. In addition, in the blocking condition, amphetamine tended to alleviate shock-induced suppression. This was supported by the group $\times$ drug interaction, which approached significance $[F(1,55)=2.71, p<.11]$.

\section{Stage 2}

Figure 2 presents the mean suppression ratios over four blocks of two trials for the blocking and control groups in the four drug conditions (SS, SD, DS, DD). There was an overall trend toward less suppression in the control groups than in the blocking groups. This finding was supported by a $2 \times 2 \times 2 \times 8$ ANOVA-with main factors of drug in Stage 1 (amphetamine, saline), drug in Stage 2 (amphetamine, saline) and group (control, blocking), and a repeated measures factor of trials-which yielded a significant main effect of group $[F(1,51)=24.82$, $p<.001]$, as well as a significant group $\times$ trials interaction $[F(7,357)=3.27, p<.005]$. In addition, animals injected with amphetamine in Stage 2 were less suppressed than were animals injected with saline in Stage 2, irrespective of the drug condition in Stage 1. This finding was supported by a significant main effect of drug in Stage 2 $[F(1,51)=6.07, p<.02]$, as well as by the significant interaction of this factor with trials $[F(7,357)=3.58$, 


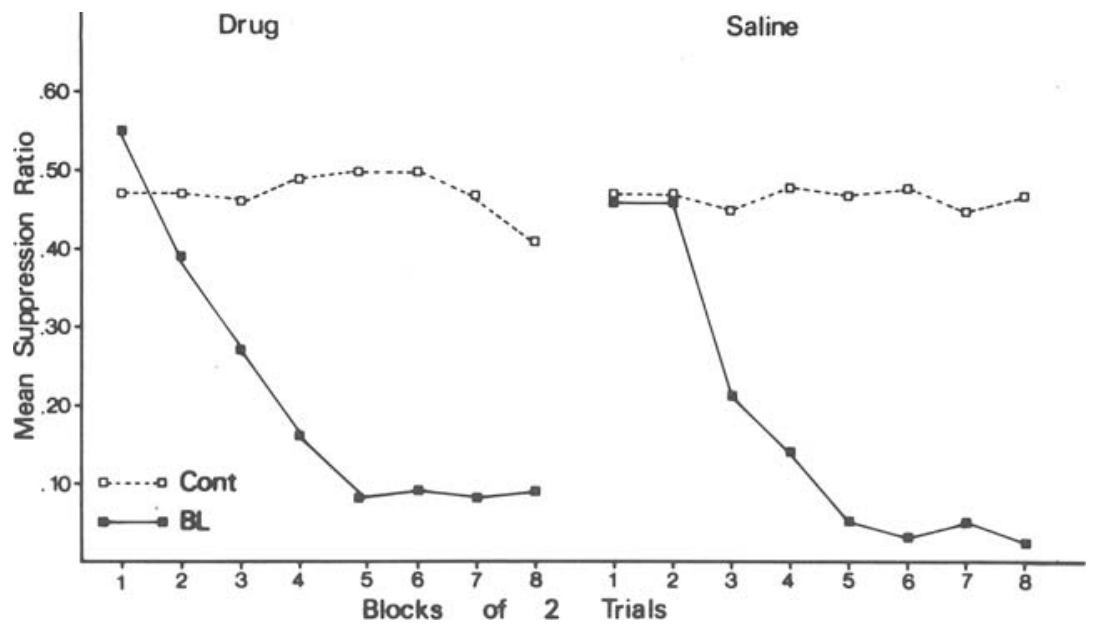

Figure 1. Mean suppression ratios over eight blocks of two trials in Stage 1 (CS: noise) of the blocking (BL) and control (Cont) groups under two conditions (Drug [amphetamine] and Saline).

$p<.002$ ]. However, it can be seen in Figure 2 that the reduced amount of suppression under amphetamine was confined to the control conditions. This outcome was supported by the significant interaction of group $\times$ drug in Stage $2[F(1,51)=13.62, p<.001]$, as well as by the interaction of group $\times$ drug in Stage $2 \times$ trials $[F(7,357)$ $=2.58, p<.02]$. Separate $t$ tests based on the error term of the ANOVA revealed that amphetamine alleviated suppressed responding in the control animals injected with saline in Stage 1 [overall mean suppression ratios were 0.42 for Control Group SD and 0.13 for Control Group SS; $t(51)=2.99, p<.005]$. A similar pattern emerged in the control animals injected with amphetamine in Stage 1 [overall mean suppression ratios were 0.35 for Control Group DD and 0.17 for Control Group DS; $t$ (51) $=1.86, p<.10]$.

\section{Test}

Figure 3 presents the mean suppression ratios over four test trials for the control and blocking groups in the four drug conditions (SS, SD, DS, DD). Figure 4 presents the overall mean suppression ratios of all eight groups. As can be seen in Figure 3, there was an overall tendency for the blocking groups to exhibit less suppression than the control groups. This finding was supported by a $2 \times 2 \times 2 \times 4$ ANOVA-with main factors of drug in Stage 1 (amphetamine, saline), drug in Stage 2 (amphetamine, saline) and group (control, blocking), and a repeated measures factor of trials-which yielded a significant main effect of group $[F(1,51)=12.75, p<.001]$, as well as a significant group $\times$ trials interaction $[F(3,153)=4.86$, $p<.003]$. In addition, the three-way interaction of the main effects was significant $[F(1,51)=10.71$, $p<.002]$. As can be seen in Figures 3 and 4 , this interaction reflects the fact that the blocking effect was present in the SS and DD conditions but not in the SD and DS conditions. In order to determine the presence of blocking in each of the four drug conditions, separate $t$ tests based on the error term of the ANOVA were carried out to compare the mean suppression ratios of the blocking and control groups. Significant differences in the suppression ratios were obtained in the SS condition $[t(51)=$

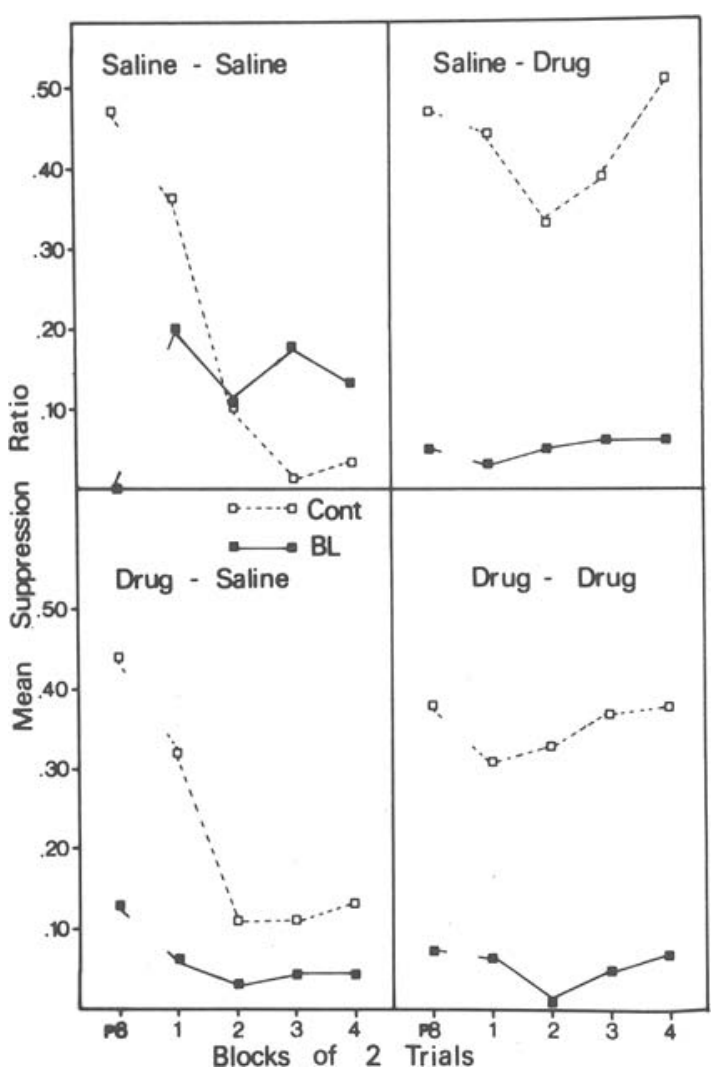

Figure 2. Mean suppression ratios over four blocks of two trials in Stage 2 (CS: noise/light) and the last trial of Stage 1 (p8) of the blocking (BL) and control (Cont) groups under four drug conditions in Stage 1 and Stage 2 (Saline-Saline, Salime-Drug, Drug-Saline, and Drug-Drug). 


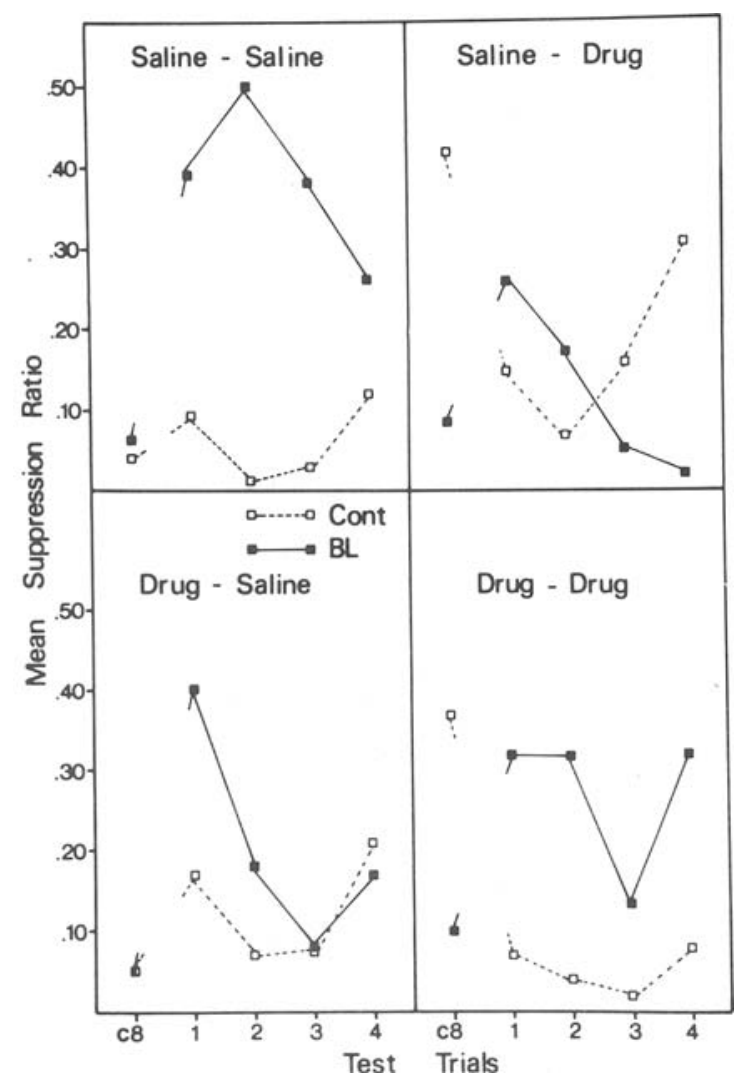

Figure 3. Mean supprexion ratios over four trials in test (CS: light) and the last trial of Stage 2 (c8) of the blocking (BL) and control (Cont) groups under four drug conditions in Stage 1 and Stage 2 (Saline-Saline, Saline-Drug, Drug-Saline, and Drug-Drug). No drugs were given in test.

$3.22, p<.005]$ and in the DD condition $[t(51)=2.20$, $p<.05]$. In contrast, no significant difference was obtained in the SD condition $[t(51)=-0.03]$ or in the DS condition $[t(51)=0.76]$. As can be seen in Figure 4, the absence of the blocking effect in the SD and DS conditions, as compared with the SS and DD conditions, stems from weaker suppression in the control groups as well as stronger suppression in the blocking groups.

\section{DISCUSSION}

The results of the present study may be summarized as follows: Prior conditioning to one component (noise) of a compound CS (noise + light) blocked conditioning to the second component (light) in the SS condition. The administration of the drug in either stage alone disrupted blocking. In contrast, animals that received amphetamine in both stages of the blocking paradigm showed a normal blocking effect.

As was elaborated in the introduction, the present experiment was initiated because of the finding that amphetamine disrupts $\mathrm{LI}$ and on the assumption that blocking and LI share a common mechanism (learning to ignore an irrelevant stimulus). However, in contrast to results obtained in studies of LI, in which the administration of the drug in Stage 1 (nonreinforced preexposure) and Stage 2 (conditioning) led to the abolition of LI, in the blocking paradigm the administration of amphetamine in Stage 1 (single stimulus conditioning) and Stage 2 (compound conditioning) left blocking intact. These results suggest that the two phenomena may not be governed by a common mechanism (Wagner \& Rescorla, 1972). Alternatively, it is possible that both paradigms involve the process of learning to ignore an irrelevant stimulus, but that they differ in the conditions under which this process takes place, leading to differential effects of amphetamine. In blocking, the information of relevance and irrelevance is signaled by two distinct stimuli, and the stimulus to be ignored comes to predict an outcome already signaled by another stimulus; that is, it provides no new information about reinforcement. In LI, the same stimulus signals conflicting information of relevance and irrelevance, and the stimulus to be ignored in Stage 1 comes to predict a new, significant outcome (i.e., reinforcement) in Stage 2. Thus, both blocking and LI may involve learning to ignore an irrelevant stimulus, but to display LI, animals must con-

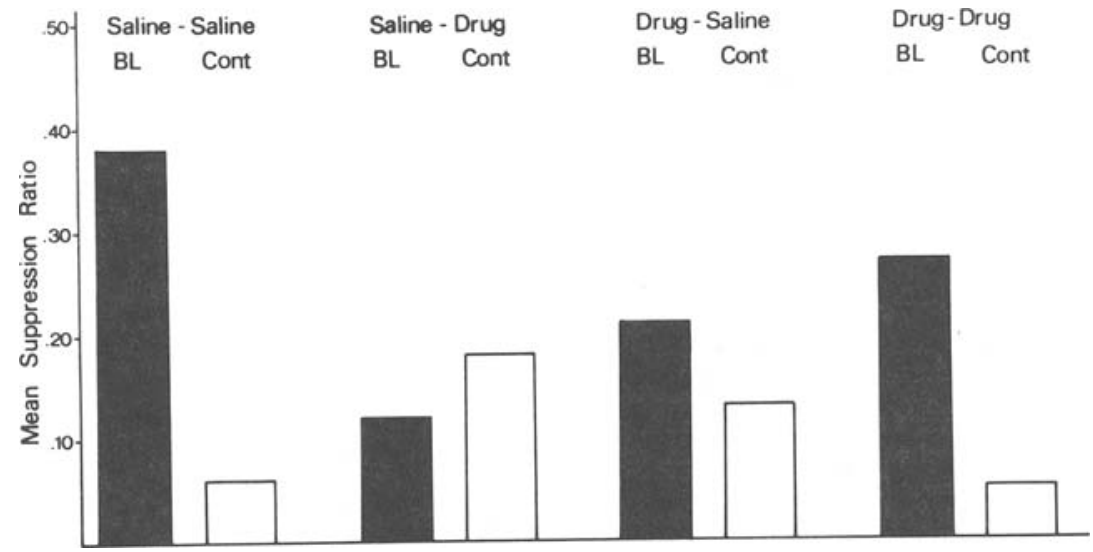

Figure 4. Mean suppression ratios in test (CS: light) of the blocking (BL) and control (Cont) groups under four drug conditions in Stage 1 and Stage 2 (Saline-Saline, Saline-Drug, DrugSaline, and Drug-Drug). No drugs were given in test. 
tinue to respond to the stimulus as irrelevant in spite of the fact that it is followed by reinforcement. The finding that LI, but not blocking, is disrupted by amphetamine suggests that the drug does not disrupt animals' ability to learn that a given stimulus is irrelevant, but, instead, disrupts their ability to respond to a stimulus as irrelevant under changed contingencies of reinforcement. More generally, these results suggest that amphetamine affects reinforcement switching mechanisms (as in LD), but not stimulus switching mechanisms (as in blocking).

This suggestion is supported by data from two additional sources, namely, the partial reinforcement extinction effect (PREE) and discrimination reversal. In the PREE, animals trained on partial reinforcement and switched to extinction show a retarded rate of extinction, compared to continuously reinforced animals. Under amphetamine, this effect is abolished; that is, partially reinforced animals extinguish as rapidly as their continuously reinforced counterparts (Weiner, Bercovitz, Lubow, \& Feldon, 1985). In discrimination reversal, animals are trained on one discrimination and then switched to a different discrimination in which the reinforcement contingencies of the original discriminative stimuli are reversed. Animals under amphetamine exhibit facilitated reversal learning due to a rapid shift of choices to the new S+ (Weiner, Ben-Horin, \& Feldon, 1986; Weiner \& Feldon, 1986; Weiner, Feldon, \& Ben-Shahar, 1986). These results suggest that in two-stage paradigms that involve a change in reinforcement contingencies from Stage 1 to Stage 2, and in which normal animals continue to respond in Stage 2 according to the reinforcement contingencies of Stage 1, animals under amphetamine exhibit a rapid switch of responding according to the changed contingencies of Stage 2. Since blocking does not involve a switch of reinforcement contingencies from Stage 1 to Stage 2, amphetamine has no effect on this phenomenon.

The rate of conditioning under changed contingencies of reinforcement is considered to reflect the amount of attention to, or the associability of, the CSs: Reduced attention to stimuli leads to poorer subsequent conditioning, whereas increased attention to stimuli results in faster future learning (Lubow et al., 1981; Mackintosh, 1983). Thus, amphetamine-produced rapid learning under changed contingencies of reinforcement suggests that the drug enhances the attention to, or the associability of, the CSs. Although such rapid learning can sometimes appear as facilitation, as in the case of reversal, or as retardation, as in the case of LI and PREE, it points in all cases to a failure in applying previous experience under changed environmental conditions and to an exaggerated control of the prevailing situational demands. This phenomenon has important implications for the animal amphetamine model of schizophrenia. An overly active attentional mechanism has been a frequently noted dysfunction of schizophrenia (e.g., Lang \& Buss, 1965; Mathysse et al., 1979; McGhie, 1977; Neale \& Cromwell, 1977; Nuechterlein, 1977). Moreover, the schizophrenia deficit has been described as an inability to maintain a major response set or a dominant interpretation of a given situation, excessive yielding to the immediate situational demands, and enhanced switching from one associative content to another (e.g., Bleuler, 1966; Broen, 1968; Frith, 1979; Magaro, 1980; Payne, 1966; Shakow, 1962). Amphetamine-produced rapid response switching under changed contingencies of reinforcement may provide an animal analogue to these features of the clinical syndrome.

The second result obtained in the present study was the attenuation of blocking in animals that received amphetamine in either Stage 1 or Stage 2 alone. As stated in the introduction, the administration of the drug in each stage alone was modeled after our experiments with LI. However, the effects of amphetamine in the blocking procedure were different from those obtained in the LI paradigm, in which the administration of the drug in either stage alone did not disrupt LI. The fact that both SD and DS animals failed to show blocking suggests that in both conditions the disruption of blocking was due to a change in drug state between the two stages. It has been extensively documented that operations that introduce a change in the experimental parameters from Stage 1 to Stage 2 (the compound conditioning stage) disrupt blocking. This unblocking effect has been obtained following changes in the intensity, duration, probability, or timing of the unconditioned stimulus (US), as well as following the addition or omission of a second event after the US (Basden \& Kleim, 1976; Dickinson, Hall, \& Mackintosh, 1976; Gray \& Appignanesi, 1973; Holland, 1984; Kamin, 1968, 1969; Mackintosh, Dickinson, \& Cotton, 1980; Mackintosh \& Turner, 1971; Neely \& Wagner, 1974; Sharp, James, \& Wagner, 1980). It is reasonable to assume that, in the present experiment, the change in drug state between the two stages, whether from drug to no drug or vice versa, similarly served as a second, surprising event that produced the unblocking phenomenon. Thus, although the drug/no-drug administration method was successful in clarifying the effects of amphetamine on $\mathrm{LI}$, this method was not useful in the case of blocking, because it caused unblocking.

Here a note is in order regarding another effect of the drug, namely the alleviation of suppression produced in the control groups during compound conditioning (Figure 2). Experimenters investigating the effects of amphetamine on conditioned emotional responses (CERs) have reported variable results. Thus, the drug may decrease (Sanger \& Blackman, 1976a, 1976b), increase (Brady, 1956; Glick, 1969), or have no effect on suppression (Lauener, 1963; Miczek, 1973; Tenen, 1967). The reason for the reduction in suppression in the present study is not clear. Furthermore, during test, which was conducted in the absence of the drug, both groups exhibited strong suppression similar to that of animals that received saline in Stage 2 (Figure 3). Interestingly, strong suppression was obtained on the first test trial, that is, before the administration of the first shock. This suggests that 
although during compound conditioning amphetaminetreated controls failed to exhibit response suppression, they did acquire the light-shock association.

Finally, our results are inconsistent with those of Crider et al. (1982), who found that animals under amphetamine in both stages did not exhibit blocking. The discrepancy between the results of the two studies is most probably due to procedural differences in both the behavioral task and the drug regime. Crider et al. used a two-way active avoidance procedure and a considerably higher drug dose ( $4 \mathrm{mg} / \mathrm{kg}$ ), administered for 5 days. These differences preclude any meaningful comparisons between the two experiments. However, it should be noted that, unlike the CER procedure, the procedure used by Crider et al. is not commonly used for demonstrating blocking.

\section{REFERENCES}

Basden, B. H., KLEIM, D. M. (1976). Unblocking as a function of shock reduction. Bulletin of the Psychonomic Society, 8, 109-111.

BLEULER, E. (1966). Dementia praecox or the group of schizophrenias. New York: International Universities Press. (Original work published 1911)

Brady, J. W. (1956). Assessment of drug effects on emotional behavior. Science, 123, 1033-1034.

BroEN, W. E. (1968). Schizophrenia: Research and theory. New York: Academic Press.

Chapman, L. J., Chapman, J. P. (1973). Disordered thought in schizophrenia. New York: Prentice-Hall.

Crider, A., Solomon, P. R., McMahon, M. A. (1982). Disruption of selective attention in the rat following d-amphetamine administration: Relationship to schizophrenic attention disorder. Biological Psychiatry, 17, 351-361.

Dickinson, A., Hall, G., Mackintosh, N. J. (1976). Surprise and the attenuation of blocking. Journal of Experimental Psychology: Animal Behavior Processes, 2, 313-322.

Frith, C. D. (1979). Consciousness, information processing and schizophrenia. British Joumal of Psychiatry, 134, 225-235.

GArmezY, N. (1977). The psychology and psychopathology of attention. Schizophrenia Bulletin, 3, 360-368.

GLICK, S. D. (1969). Effects of d-amphetamine and frontal ablations on response suppression in rats. Journal of Comparative \& Physiological Psychology, 69, 49-54.

Gray, T., ApPignanesi, A. A. (1973). Compound conditioning: Elimination of the blocking effect. Leaming \& Motivation, 4, 374-380.

Holland, P. C. (1984). Unblocking in Pavlovian appetitive conditioning. Joumal of Experimental Psychology: Animal Behavior Processes, 10, 476-497.

KAMIN, L. J. (1968). "Attention-like" processes in classical conditioning. In M. R. Jones (Ed.), Miami symposium on the prediction of behavior. Miami: University of Miami Press.

KAmIn, J. J. (1969). Predictability, surprise, attention and conditioning. In B. A. Camphell \& R. M. Church (Eds.), Punishment and aversive behavior. New York: Appleton-Century-Crofts.

Koxkinidis, L., a Anisman, R. M. (1980). Amphetamine models of paranoid schizophrenia: An overview and elaboration of animal experimentation. Psychological Bulletin, 3, 551-579.

Lang, P. J., \& Buss, A. H. (1965). Psychological deficit in schizophrenia: II. Interference and activation. Joumal of Abnormal Psychology, 70, 77-106.

LAUENER, H. (1963). Conditioned suppression in rats and the effects of pharmacological agents thereon. Psychophamacologia, 4, 311-325.

Lubow, R. E. (1973). Latent inhibition. Psychological Bulletin, 79, 398-407.

Lubow, R. E., Weiner, I., SCHNUR, P. (1981). Conditioned atten- tion theory. In G. H. Bower (Ed.), The psychology of learning and motivation (Vol. 15). New York: Academic Press.

Mackintosh, N. J. (1973). Stimulus selection: Learning to ignore stimuli that predict no change in reinforcement. In $\mathbf{R}$. A. Hinde \& J. S. Hinde (Eds.), Constraints on learning: Limitations and predispositions. Cambridge, England: Academic Press.

MACKINTOSH, N. J. (1975). A theory of attention: Variations in the associability of stimuli with reinforcement. Psychological Review, 82 , 276-298.

MaCkINTOSH, N. J. (1983). Conditioning and associative learning. Oxford: Oxford University Press.

Mackintosh, N. J., Dickinson, A., Cotton, M. M. (1980). Surprise and blocking: Effects of the number of compound trials. Animal Learning \& Behavior, 8, 387.391.

Mackintosh, N. J., TuRner, C. (1971). Blocking as a function of novelty of CS and predictability of UCS. Quarterly Journal of Experimental Psychology, 23, 359-366.

Margo, P. A. (1980). Cognition in schizophrenia and paranoia: The integration of cognitive processes. Hillsdale, NJ: Erlbaum.

Matthysse, S., Spring, B. J., \& Sugarman, J. (EDs.) (1979). Attention and information processing in schizophrenia. Oxford: Pergamon Press.

McGHIE, A. (1977). Attention and perception in schizophrenia. In B. A. Maher (Ed.), Contributions to the psychopathology of schizophrenia. New York: Academic Press.

MICZEK, K. A. (1973). Effects of scopolamine, amphetamine and benzodiazepines on conditioned suppression. Pharmacology, Biochemistry \& Behavior, 1, 401-411.

MOORE, J. W. (1979). Brain processes and conditioning. In A. Dickinson \& R. A. Boakes (Eds.), Mechanisms of learning and motivation: A memorial volume for Jerzy Konorski. Hillsdale, NJ: Erlbaum.

Neale, J. M., \& Cromwell, R. L. (1977). Attention in schizophrenia. In B. A. Maher (Ed.), Contributions to the psychopathology of schizophrenia. New York: Academic Press.

NEELY, J., \& WAGNER, A. R. (1974). Attenuation of blocking with shifts in reward: The involvement of schedule-generated contextual cues. Journal of Experimental Psychology, 102, 751-763.

NuechterleIN, K. H. (1977). Reaction time and attention in schizophrenia: A critical evaluation of the data and theories. Schizophrenia Bulletin, 3, 373-428.

PAYNE, R. W. (1966). The measurement and significance of overinclusive thinking and retardation in schizophrenia patients. In P. Hock \& J. Zubin (Eds.), Psychopathology of schizophrenia (pp. 77-97). New York: Gnune \& Stratton.

Sanger, D. J., Blackman, D. E. (1976a). Effects of chlordiazepox ide, ripazepam and d-amphetamine on conditioned acceleration of timing behavior in rats. Psychopharmacology, 48, 209-215.

SANGER, D. J., \& BLACKMAN, D. E. (1976b). The effects of d-amphetamine on the temporal control of operant responding in rats during a pre-schock stimulus. Joumal of Experimental Analysis of Behavior, 3, 369-378.

SEGAL, D. S., \& JANOWSKY, D. S. (1978). Psychostimulant-induced behavioral effects: Possible models of schizophrenia. In M. A. Lipton, A. DiMascio, \& K. E. Killam (Eds.), Psychopharmacology: A generation of progress. New York: Raven Press.

SEGAL, D. S., \&CHUCKrT, M. A. (1983). Animal models of stimulantinduced psychosis. In I. Creese (Ed.), Stimulants: Behavioral and technical perspectives. New York: Raven Press.

Shakow, D. (1962). Segmental set: A theory of the formal psychological deficit in schizophrenia. Archives of General Psychiatry, 6, 17-33.

SharP, P. E., JAMES, J. H., WAGNER, A. R. (1980). Habituation of a "blocked" stimulus during Pavlovian conditioning. Bulletin of the Psychonomic Society, 15, 139-142.

Solomon, P. R., Crider, A., Winkelman, J. W., Turi, A., Kamer, R. M., KAPLAN, L. J. (1981). Disrupted latent inhibition in the rat with chronic amphetamine or haloperidol-induced supersensitivity: Relationship to schizophrenic attention disorder. Biological Psychiatry, 16, 519-537.

Tenen, S. S. (1967). Recovery time as a measure of CER strength: 
Effects of benzodiazepines, amobarbital, chlorpromazine and amphetamine. Psychopharmacologia, 12, 1-17.

VENABLES, P. H. (1964). Input dysfunction in schizophrenia. In B. A. Maher (Ed.), Progress in experimental personality research (Vol. 1). New York: Academic Press.

Wagner, A. R., \& Rescorla, R. A. (1972). Inhibition in Pavlovian conditioning: Application of a theory. In R. A. Boakes \& M. S. Halliday (Eds.), Inhibition and learning. New York: Academic Press.

Weiner, I., Ben-Horin, E., Feldon, J. (1986). Amphetamine and the overtraining reversal effect. Pharmacology, Biochemistry \& Behavior, 24, 1539-1542.

Weiner, I., Bercovitz, H., Lubow, R. E., \& Feldon, J. (1985). The abolition of the partial reinforcement extinction effect (PREE) by amphetamine. Psychopharmacology, 86, 318-323.

WEINER, I., \& FELDON, J. (1986). Reversal and nonreversal shifts under amphetamine. Psychopharmacology, 89, 355-359.
Weiner, I., Feldon, J., \& Ben-Shahar, O. (1986). Simultaneous brightness discrimination and reversal: The effects of amphetamine administration in the two stages. Pharmacology, Biochemistry \& Behavior, 25, 939-942.

Weiner, I., Lubow, R. E., \& Feldon, J. (1981). Chronic amphetamine and latent inhibition. Behavioral Brain Research, 2, 285-286. Weiner, I., Lubow, R. E., Feldon, J. (1984). Abolition of the expression but not the acquisition of latent inhibition by chronic amphetamine in rats. Psychopharmacology, 83, 194-199.

WeIner, I., LuBow, R. E., \& Feldon, J. (1986). Disruption of latent inhibition by acute amphetamine administration. Manuscript submitted for publication.

(Manuscript received October 15, 1985; revision accepted for publication November 14, 1986.) 